Michener's weighty epic Space (particularly the scenes at the US Navy test centre at Patuxent River, Maryland, which presumably drew on a common fund of experience). Matters sag, somewhat, as Kluger displays the extent of his researches with interminable reconstructed mission-controllathons. Here is one:

"Ten minutes to burn," Haise announced. Shortly afterward he called, "Eight minutes to burn," then "Six minutes to burn," then "Four minutes to burn." Finally Brand, at his Capcom station, took up the call.

"Jim, you are go for the burn, go for the burn."

"Roger, I understand," Lovell said. "We are go for the burn."

Somehow the film manages to convey the technical niceties of the mission without such tedious exegesis. Nevertheless, Lost Moon is packed with information on a mission that NASA would probably rather we forgot about, and jackdaw space enthusiasts will not be deterred by the occasional attempts at literature.

The Apollo Adventure (the book of the film of the book) eschews even that. It is little more than a scrapbook of mission details, accounts of the filming and assorted Apollo miscellany that Lovell and Kluger were unable to cram into the earlier book. These include transcripts of astronauts bitching about their employers, no more interesting than one would expect for them having been classified until recently. The design and production are tacky: the random pepperings of spacecraft schematics would be great were one the kind of person (God forbid) who absolutely has to know the location of every storage compartment in the command module - except that the printing is too indistinct to read. Save your money and see the film instead.

Henry Gee is an assistant editor of Nature.

\title{
Nature lovers and other villains
}

\author{
Stuart L. Pimm
}

\section{Nature's Keepers: The New Science of Nature Management. By Stephen Budiansky. Free Press/Weidenfeld and Nicolson: 1995. Pp. 310. \$25, £18.99.}

ONF judges a book not by its cover but by the quotations that adorn it. Ennobled by the statement on the back of Nature's Keepers that "modern ecological research is providing the tools for effective nature management", ecologists ought to ask for more money. Yet the volume also carries praise from Gregg Easterbrook, author of A Moment on the Earth, a deeply flawed book that spawned a vigorous Internetbased competition this summer to see who could find the most scientific errors per page. So is Nature's Keepers another book trashing science, conveniently timed to appear just as the US Congress is contemplating reversing its long and impressive record of protecting nature? The text is as divided as its cover.

In "the cult of the wild", the book impales nature lovers who revere William Wordsworth, the poet, or Chief Seattle, the American Indian ecological prophet. Wordsworth did not want his daffodils appreciated by the untutored, workingclass hordes that a proposed railroad would bring. And Chief Seattle's famous speech — "Earth does not belong to man, man belongs to Earth" - is a fabrication of a modern film script. $\mathrm{He}$ evidently said nothing about the environment. Debunking myths is wicked fun. It also misses the point. Christmas is still deeply significant to Christians who know that decorated trees are a Victorian import, that 25 December is suspiciously close to the date of pagan winter-solstice rituals and that astronomical explanations for the Star of Bethlehem (comets, supernovae) came in the wrong month of the wrong year. Historically, Amerindians may have exterminated most of the large vertebrates they encountered, but we should not denigrate their modern religious beliefs about the environment.

Next comes "the science (but mostly politics) of nature management". Ecologists are praised for knowing that "disturbance" and "change" typify nature

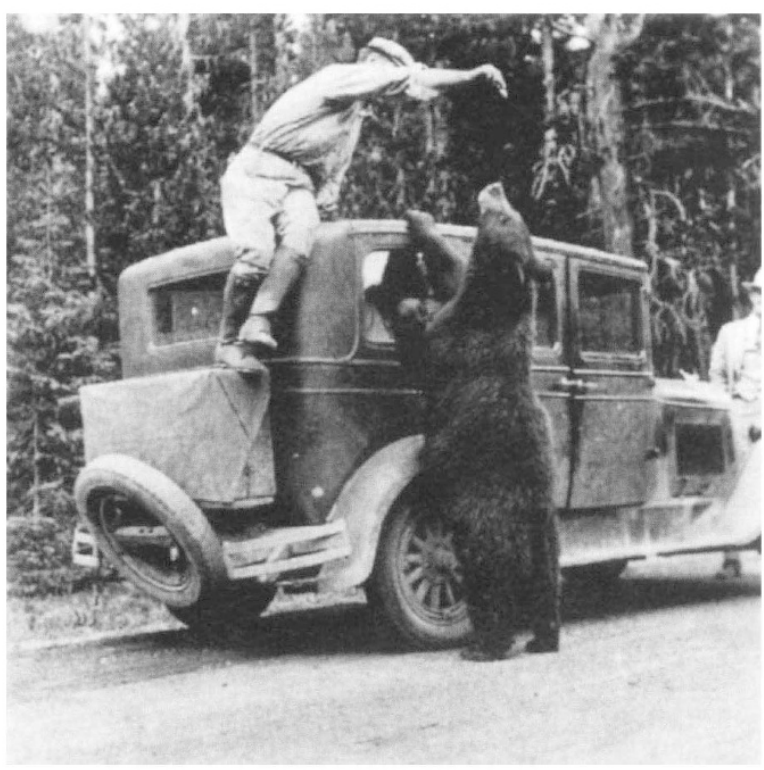

From The Grizzly Bears of Yellowstone: Their Ecology in the Yellowstone Ecosystem, 1959-1992 by J. J. Craighead, J. S. Sumner and J. A. Mitchell. Island, \$100. better than "constancy" and "balance". They will not delight in their characterization as the smart heroes who oppose the ignorant, evil managers of national parks. With hindsight, ecologists might have decided to do things differently at Yellowstone or Tsavo. Nevertheless, those who manage fire or large mammals in parks that are token remnants of the original native ecosystems have awesome tasks to perform.

Finally, we meet the theoreticians, still waiting for a modern Newton to give them a grand synthesis. Budiansky writes at length and fairly accurately about grouse, fisheries, the restoration of oak-savannas and which species one cannot remove from food webs without dire consequences. Those expecting victims will not be disappointed. Edward O. Wilson is described as "a relentless popularizer" whose conclusions "are something closer to politics than science" and as the known collaborator of "misanthropic" Paul Ehrlich, the "over-population guru".

The subject is extinction rates. We are told to be surprised that the observed rate "is not 50,000 species per year, but one species a year". Only those who read footnotes will find that Budiansky derives this estimate from a sample of one in 2,000 species. So the yearly total is in fact 2,000 extinctions - a rate that will surely increase at least tenfold in the coming decades for reasons Budiansky discusses. A yearly rate of 20,000 extinctions is within a factor of three of Wilson's muchderided estimate, yet four orders of magnitude greater than the rate implied in the main text.

The arithmetic also fails when Budiansky discusses the relationship between the number of species an area contains and its size. This is the key concept underpinning predictions of the extinctions that follow habitat losses. He quotes an "unintended parody of the entire concept" in a novel whose hero finds 200 beetles within a square mile, then estimates that within a day's drive there will be 500,000 species. Knowing that species numbers increase under such circumstances in proportion to no more than the one-tenth to one-fifth power of the area, ecologists predict 650 to 2,100 species within a $200-$ mile radius. Far from being a parody, their predictions (unlike the hero's) are reasonable. So too are their estimates of species losses following habitat destruction.

For someone who can write engagingly and some- 
times incisively about environmental issues, Budiansky consistently misses the big questions. There are difficult ethical and economic choices in how we value biological diversity. Those who manage this diversity face not only scientific uncertainty but also the knowledge that their actions may take decades to unfold, time in which society's values may change. Scientists who predict high future extinction rates are not omniscient, but believe, simply, that ignorance is not bliss. How sad that Budiansky misses the chance to write thoughtfully about the interfaces between nature, ethics, economics and our future.

Stuart L. Pimm is in the Department of Ecology and Evolutionary Biology, University of Tennessee, Knoxville, Tennessee 37996, USA.

\section{Ways of seeing}

\section{David Knight}

\section{A History of Scientific Thought: Elements of a History of Science. Edited by Michel Serres. Blackwell: 1995. Pp. 760. £75, \$100.}

THEY order things differently in France, and it is good for outsiders to see how things look there. Although the dust jacket has a portrait of Michael Faraday in his laboratory, inside he makes only a passing appearance in one sentence (like God in the Origin of Species); the book does not cover everything. It is striking that we do not get to Galileo until page 280 , and to the nineteenth century until about page 400: despite the exponential growth of science, the focus is on beginnings. The book is not intended as a work of reference; rather, it is a series of meditative or considered essays, examining nodal points in the long history of science from the first emergence of experts writing on clay in Babylonia.

Michel Serres himself evokes the beginnings of geometry in Greece and then in an impressionistic tour de force calls up the Paris of the years around 1800 when it was the centre of excellence in all the sciences. He sketches the emergence of scientists as a kind of secular clergy; the shade of Auguste Comte indeed stalks through the book, and we learn about his calendar where the saints are men of science, as well as the Revolutionary calendar with its tenday weeks. Serres is bold enough to paint for us the dazzling big picture, the general plan, whereas most Anglo-Saxons, perhaps in our Baconian tradition, are more like bricklayers than architects in constructing the historical edifice.

Where it comes off, this is very splendid; and the various authors do their best to show how the events they describe are

nodal, rather like the poet-scientist $\mathbf{J}$. W. Goethe's Ur-phenomena. They do their best also to show the unexpected, the nonteleological in the history of the sciences. We know that if Humphry Davy had not isolated potassium when he did, J. J. Berzelius would have done so within a year or two; and if he had not subsequently declared the elementary nature of chlorine, then J. L. Gay-Lussac would soon have done that. There is something like inevitability in the development of science;

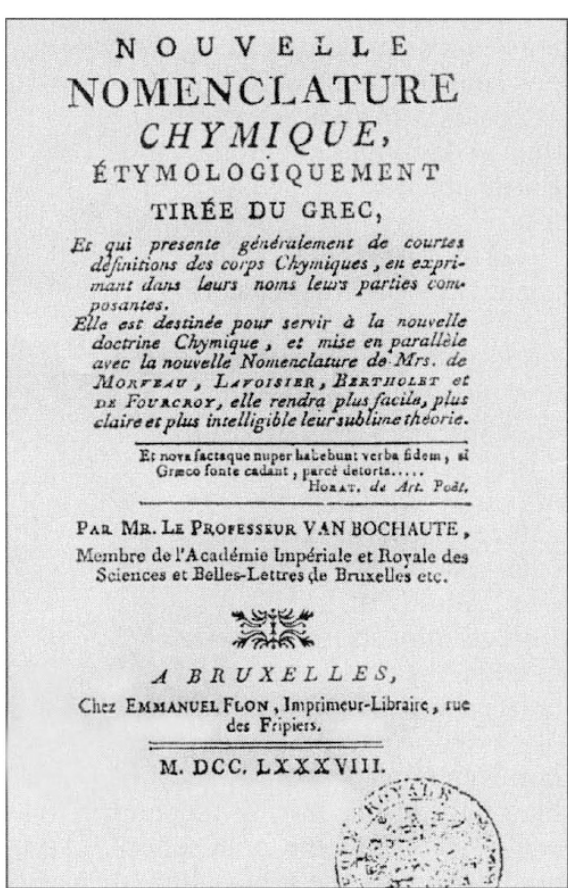

1789-1914, where specialization and exponential growth were the order of the day, the focus is on individuals: A. L. Lavoisier, Charles Lyell, Gregor Mendel and D. I. Mendeleyev. These are not surprising names, except perhaps that they include no classical physicists; there is no attempt here to revise the pantheon. Geof Bowker gives us a close textual analysis of Lyell's writing; Bernadette Bensaude-Vincent brings her usual clarity and sharpness to her studies of the chemists, placing them carefully in con-

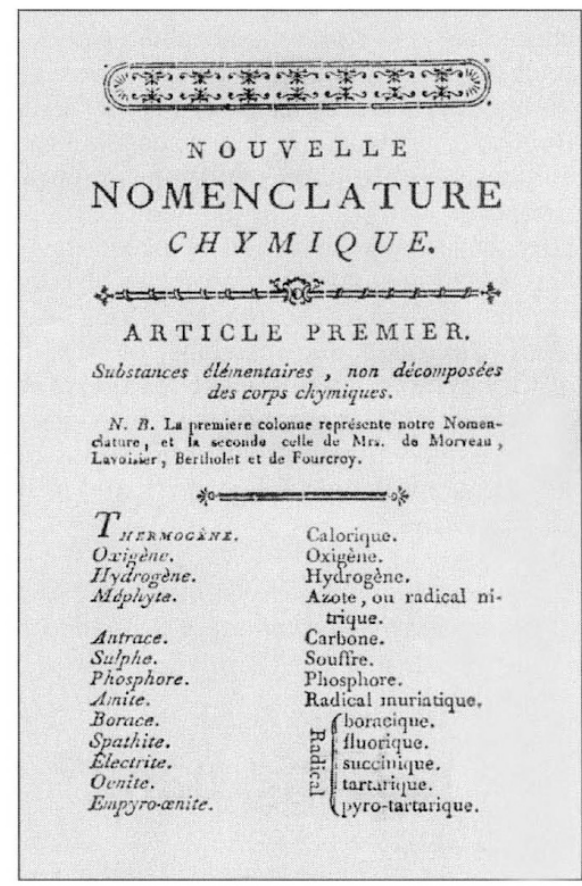

Cover and page of the Flemish chemist Karel van Bochaute's Nouvelle Nomenclature (1788). From Lavoisier in European Context: Negotiating a New Language for Chemistry edited by Bernadette Bensaude-Vincent and Ferdinando Abbri. Science History Publications, \$45.95.

but there is also the contingent, as these authors emphasize. Close examination of social context and of personal careers certainly diminishes our belief in progress and inevitability: we all know how important opportunism and career development can be. These authors take history seriously.

We find here some excellent storytelling; for example from Michel Aulthier on Archimedes, warfare and science, and from Bruno Latour on Louis Pasteur, Felix Pouchet and spontaneous generation. Others give us lucid straightforward accounts without many surprises, such as James Ritter on early mathematics, Paul Benôit and Françoise Micheau on Arab science, or Jean-Marc Drouin on naturalists and travellers. Some wear their learning lightly, such as Catherine Goldstein writing elegantly about mathematics moving from marginalia by amateurs to journal articles by professionals as Homo ludens gives way to Homo faber. Some, such as Isabelle Stengers, have written something like essay reviews for a learned journal, in her case about recent studies of Galileo, which are closer to meta-history than to narrative.

For the long nineteenth century, text - as does Drouin with Mendel, where reality and myth are particularly intertwined. These are 'exemplary' essays giving us some clues in our approach to their century; but in contrast to its close studies of the early and mediaeval periods, the book is thin in its coverage of the time when disciplines and professions were emerging, and the frontiers between sciences were being established and policed. Societies, journals, university departments, medical schools as midwives of biology and chemistry, great exhibitions, lectures stimulating the public understanding of science, addressed to the élite or to working men we learn very little of all this.

And for the twentieth century, we have a close study of devices for the oil industry; an interesting story of Frédéric Joliot and the intersection of science with politics and war; and a carefully contextual history of the computer by Pierre Lévy emphasizing the different roles played by different people with different ends, in a complex story in which one should not look for some crucial and datable foundationmoment. Here, as in the previous chapters, this approach keeps the book open for the 